\title{
LIQUEFACTION STRENGTH OF SANDS SUBJECTED TO SUSTAINED PRESSURE
}

\author{
Fumio Tatsuoka ${ }^{i)}$, Hiroyuki Kato ${ }^{(i)}$, Masaru Kimura ${ }^{(i i)}$ \\ and TEJ B.S. PRADhaN ${ }^{i v)}$
}

\begin{abstract}
Using two kinds of sands, a series of cyclic undrained triaxial tests was performed on loose and dense specimens subjected to different periods between 0.1 hour and 68 days of sustained pressure. At the same time, tests on specimens over-consolidated with an OCR of two or four were performed in order to compare the effects of long-term consolidation and over-consolidation. For each sand, the strength increase after 68 days under sustained pressure was found to be equivalent to that due to over-consolidation with an OCR of about two. It was further found that for each sand the strength increase due to long-term consolidation and over-consolidation was found to be a similar function of the plastic axial strain which had occurred during each consolidation history. This result suggests that the strength increase by these different consolidation histories is due to a similar mechanism. It was also found that strength increase due to either long-term consolidation or over-consolidation waslarger for the sand including some fines than the other clean sand.
\end{abstract}

Key words : consolidated undrained shear, earthquake, liquefaction, repeated load, sand, time effect, triaxial test (IGC : D 6/D 7)

\section{INTRODUCTION}

It has been shown that under sustained pressure the resistance to cyclic undrained loading of a clean sand(Monterey No. $0, D_{r}=$ $50 \%$; Mulilis et al., $1977 \mathrm{~b}$ ) and a coarsegrained material (Oroville gravel, $D_{50}=2.2$ $\mathrm{mm}, D_{r} \fallingdotseq 90 \%$; Baner jee et al., 1979) increase i with time. The authors also attempted to evaluate the degree of possible increases in the liquefaction strength due to sustained pressure after the compaction of sand layers of reclaimed fills of the Trans Tokyo Bay Highway Project. The present study is a part of a series of laboratory cyclic undrained testing for this project (Tatsuoka et al., 1986

i) Associate Professor, Institute of Industrial Science, University of Tokyo (IIS, UT), 22-1, Roppongi 7-chome, Minato-ku, Tokyo 106.

ii) Consulting Engineer, Chuo Kaihatsu, Co., Ltd. Formerly Visiting Research Personnel of IIS, UT.

iii) Consulting Engineer, Musashino Doshitsu Co., Ltd. Formerly Visiting Research Personnel of IIS, UT.

iv) Research Assistant, IIS, UT.

Manuscript was received for review on July 9, 1987.

Written discussions on this paper should be submitted before October 1, 1988, to the Japanese Society of Soil Mechanics and Foundation Engineering, Sugayama Bldg. 4 F, Kanda Awaji-cho 2-23, Chiyoda-ku, Tokyo 101, Japan. Upon request the closing date may be extended one month. 
a, b).

On the other hand, it has also been shown by many researchers (Ishihara and Takatsu, 1979 among others) that the resistance to cyclic undrained loading of sands increases due to over-consolidation. In the present study, cyclic undrained triaxial tests on specimens either consolidated for periods under sustained pressure or over-consolidated were performed and the results were compared. Further, a combined effect of over-consolidation and consolidation for long periods was examined.

\section{TESTING METHODS}

Materials: Toyoura sand is a natural sand with sub-angular particles $\left(G_{s}=2.64, D_{50}=\right.$ $0.16 \mathrm{~mm}, U_{c}=1.46, e_{\mathrm{max}}=0.977, e_{\mathrm{min}}=0.605$ and no fines less than $0.074 \mu \mathrm{m}$ in particle diameter). This sand has been used extensively in the study of sand liquefaction. On the other hand, Sengenyama sand is from inland deposits of the Pleistocene age with sub-angular particles $\left(G_{s}=2.71, \quad D_{50}=0.39\right.$ $\mathrm{mm}, U_{\mathrm{c}}=2.44, e_{\max }=0.918, e_{\min }=0.564$ and fines of $2.41 \%$ in weight). This sand has been used extensively for reclamation works along the seashore in the Tokyo bay area and is planned to be used for the Trans Tokyo Bay Highway Project.

Specimens of Toyoura sand were made by the air-pluviation method and those of Sengenyama sand were made by vibrating saturated specimens (the water-vibration method) ; refer to Tatsuoka et al. (1986 b) for detailed information.

The triaxial specimens were $7.5 \mathrm{~cm}$ in diameter and $15 \mathrm{~cm}$ in height with porous stone platens at the top and bottom ends. Cyclic undrained triaxial tests were performed at an isotropic confining pressure of $1.0 \mathrm{kgf} / \mathrm{cm}^{2}$ $\left(98.1 \mathrm{kN} / \mathrm{m}^{2}\right)$ for Toyoura sand or $1,333 \mathrm{kgf} /$ $\mathrm{cm}^{2}\left(131 \mathrm{kN} / \mathrm{m}^{2}\right)$ for Sengenyama sand. The test procedures were the same as described in Toki et al. (1986) and Tatsuoka et al. (1986 a, b, c) except that specimens were either over-consolidated or normally consolidated changing the period of consolidation

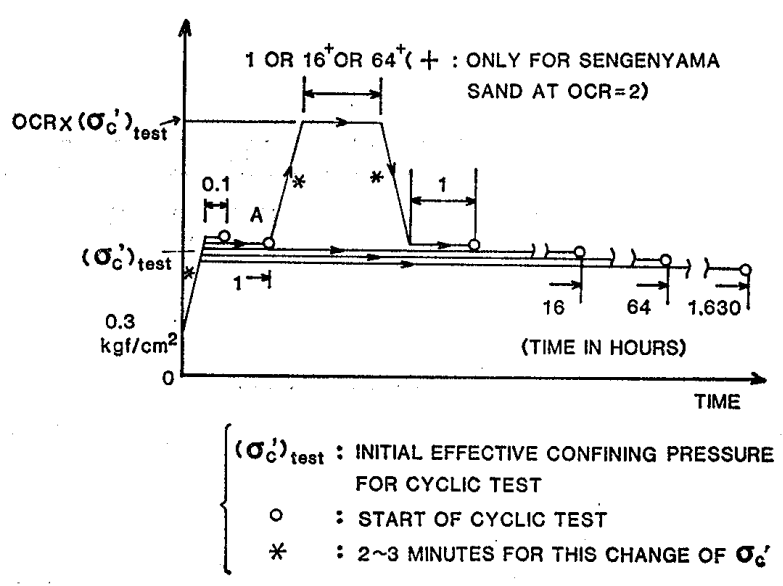

Fig. 1. Schematic diagram showing consolidation methods (the loading piston is guided by means of two linear-motion bearings with no-sealing)

(a)

(b)

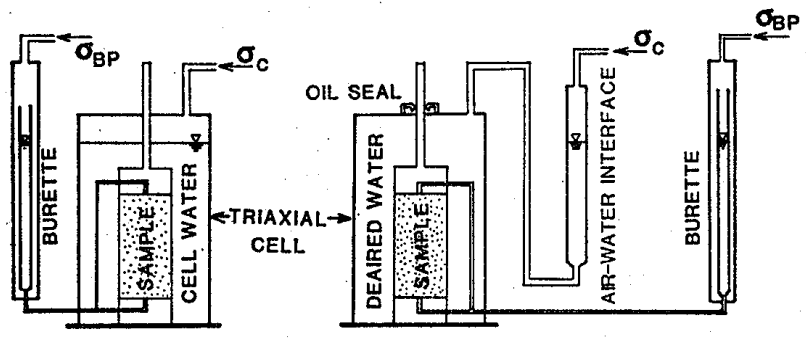

LEGEND: $\left\{\begin{array}{l}\sigma_{\mathrm{C}}: \text { CELL AIR-PRESSURE } \\ \sigma_{\text {BP }}: \text { BACK AIR-PRESSURE }\end{array}\right.$

Fig. 2. Set-up for (a) cyclic undrained loading and short-term consolidation and (b) long-term consolidation for 68 days

between 0.1 hour and about 1, 630 hours (68 days) (Fig. 1).

For long-term consolidation of 68 days, the triaxial chambers were completely filled with de-aired water (Fig.2(b)). Even for such long-term consolidation a pneumatic pressurizing method was used; compressed air was usually supplied by an air-compressor with a back-up pressure supply of compressed nitrogen $\left(\mathrm{N}_{2}\right)$ gas through a high-pressure selector. The $\mathrm{N}_{2}$ gas pressure was set lower than that by the air-compressor so that the $\mathrm{N}_{2}$ gas is to be supplied only in the case of unexpected stop of the air-compressor. Prior to cyclic testing, a part of the cell water was removed as shown in Fig. 2(a). The other specimens were consolidated as shown 


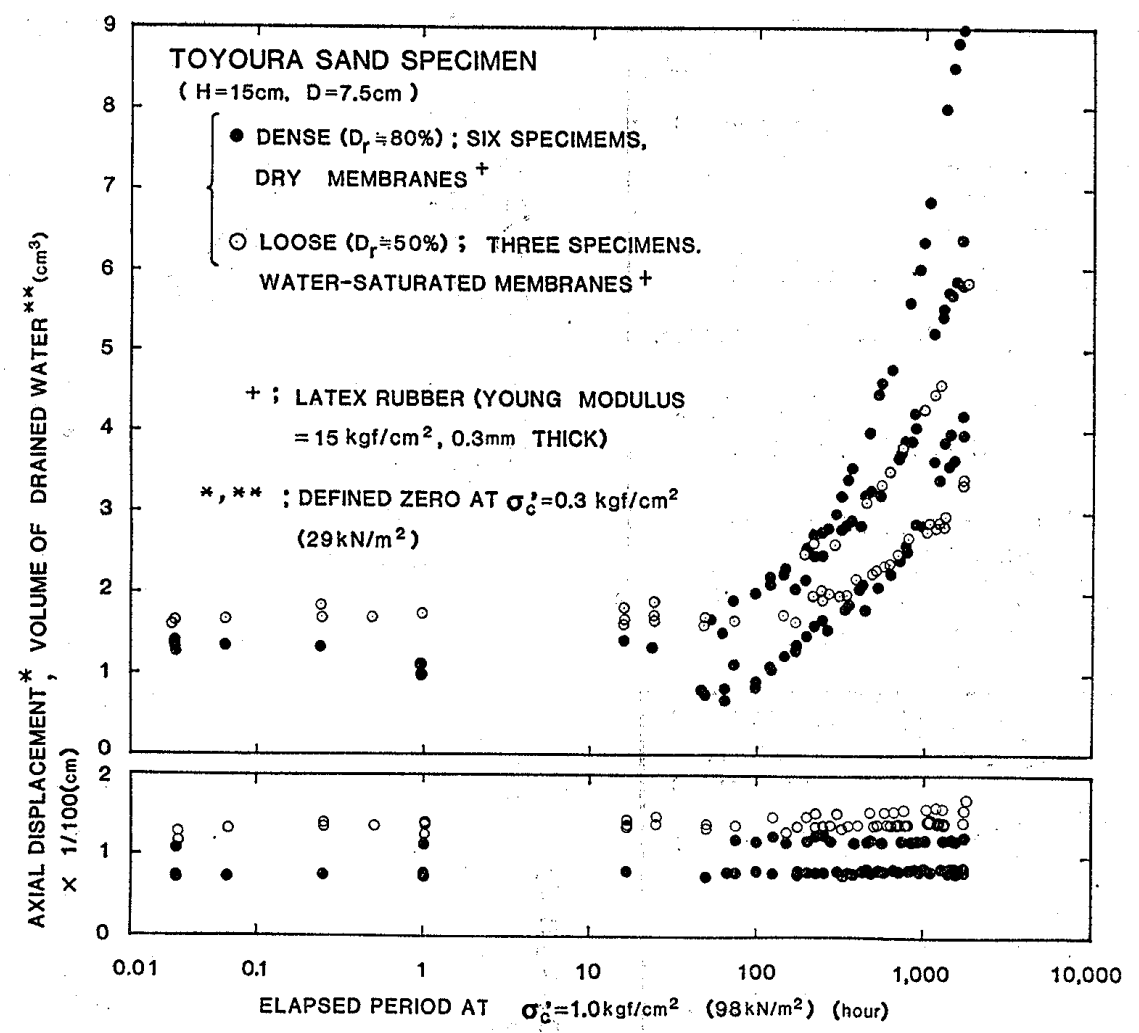

Fig. 3. Typical changes of (a) volume of drained water and (b) axial compression during consolidation

in Fig. 2(a).

A back pressure of $2.0 \mathrm{kgf} / \mathrm{cm}^{2}\left(196 \mathrm{kN} / \mathrm{m}^{2}\right)$ was used in all the tests. The $B$-values for all the specimens measured just prior to cyclic testing were greater than 0.96.

It was found that during long-term consolidation the volume of water in a burette changed not in accordance with the change of specimen height (Fig. 3). When an initially dry latex rubber membrane was used, the volume of water in a burette decreased during the first stage of consolidation. This behavior is probably due to the pore water absorbed by the membrane, but not due to the resolution of remaining air bubbles into pore water, since specimens had been well backpressurized. This initial decrease in the volume of water in a burette did not occur when an initially water-saturated membrane was used, indicating that the above idea seems to be correct. It was also found that after about 100 hours the cell water started to penetrate the membrane. Therefore, in the present study, the volume change of spec- imen during long-term consolidation could not be obtained from the volume change of water in a burette, but was inferred from the measured axial deformation by using the ratio of volume change to axial deformation measured during short-term isotropic compression tests. The volume change for longterm consolidation from one hour to 68 days thus estimated was found to be very small, since the increase in axial strain was of the order of $0.01 \%$ (see Fig. 13). This value corresponds to the change in density of the order of $0.2 \%$ in terms of relative density in percentage.

\section{TEST RESULTS}

Strength Increase; Dense $\left(D_{r . c}=80\right)$ and loose $\left(D_{r . c}=50\right)$. specimens of Toyoura sand were tested (Figs. 4 and 5). $D_{r . c}$ denotes the relative density of specimen during cyclic loading. Typical stress paths and stressstrain relations of specimens consolidated for a period of 0.1 hour or 1,630 hours are com- 

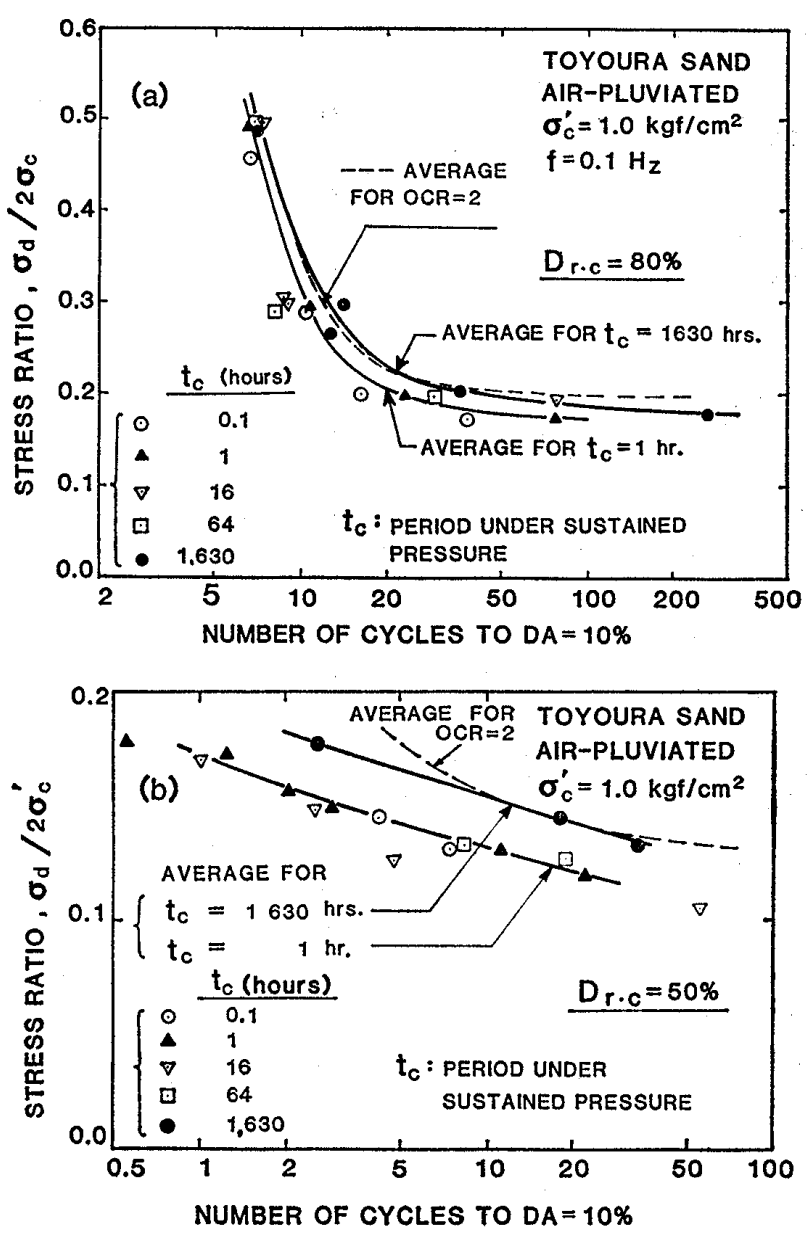

Fig. 4. Effects of long-term consolidation on liquefaction strength for (a) dense and (b) loose Toyoura sand (Tatsuoka et al., 1986c)

pared in Figs. 6 and 7. The numbers of cycles $N_{c}$ to a double amplitude axial strain $(D A)$ of $10 \%$ for each cyclic stress ratio $\sigma_{d}$ $2 \sigma_{c}{ }^{\prime}$ as shown in these figures were obtained as follows. For specimens normally consolidated for one hour, the relationship between $D_{r . c}$ and $N_{c}$ to $D A=10 \%$ was determined for each cyclic stress ratio. The values of $N_{c}$ for $D_{r . c}=50 \%$ or $80 \%$ were obtained from these relationships (refer to Fig. 7 of Tatsuoka et al., $1986 \mathrm{~b}$ ). In the other cases, the value of $D_{r . c}$ for each specimen was slightly different from $80 \%$ or $50 \%$ with the difference being less than about $\pm 5 \%$ (in terms of $D_{r . c}$ in percentage) for $D_{r . c}=80 \%$, or about $\pm 10 \%$ (in terms of $D_{\text {r.c }}$ in percentage) for $D_{r . c}=50 \%$. Therefore, $N_{c}$ to $D A=10 \%$ for each specimen was corrected to that for $D_{r . c}=$
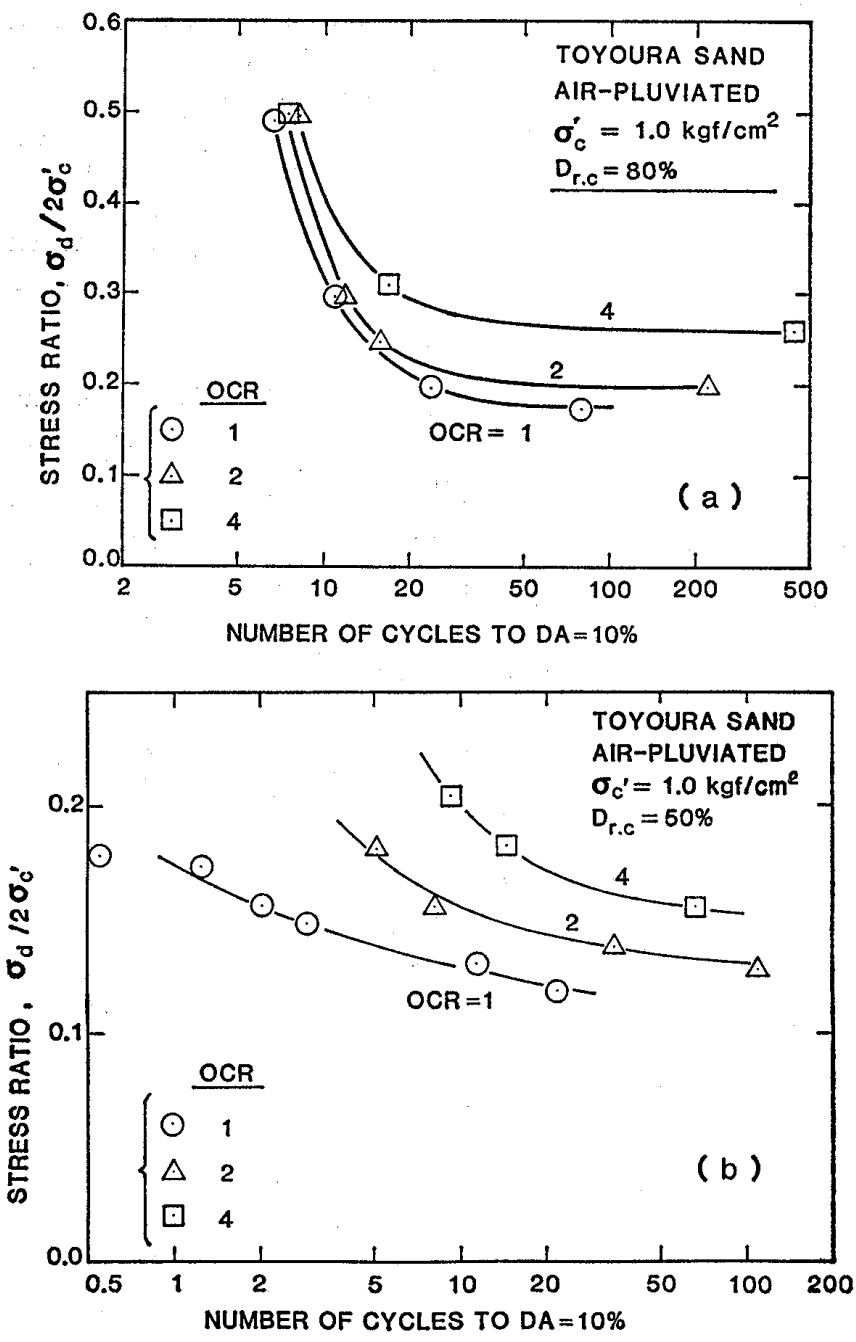

Fig. 5. Effects of over-consolidation on liquefaction strength of (a) dense and (b) loose Toyoura sand

$80 \%$ or $50 \%$ by using the relationships between $D_{r . c}$ and $N_{c}$ to $D A=10 \%$ for each of cyclic stress ratio determined for specimens normally consolidated for one hour. This correction assumed that the change of $N_{c}$ to a certain value of $D A$ due to the change of $D_{r . c}$ is the same for the same strength among normally consolidated specimens with varying periods of consolidation and over-consolidated specimens.

It has been observed that the deformation of specimen is reasonably uniform until $D A$ becomes about $10 \%$, whereas the degree of non-uniform deformation increases after $D A$ becomes about 10\% (Tatsuoka et al., $1986 \mathrm{c}$ ). Consequently, it seems that a value of $D A=$ 


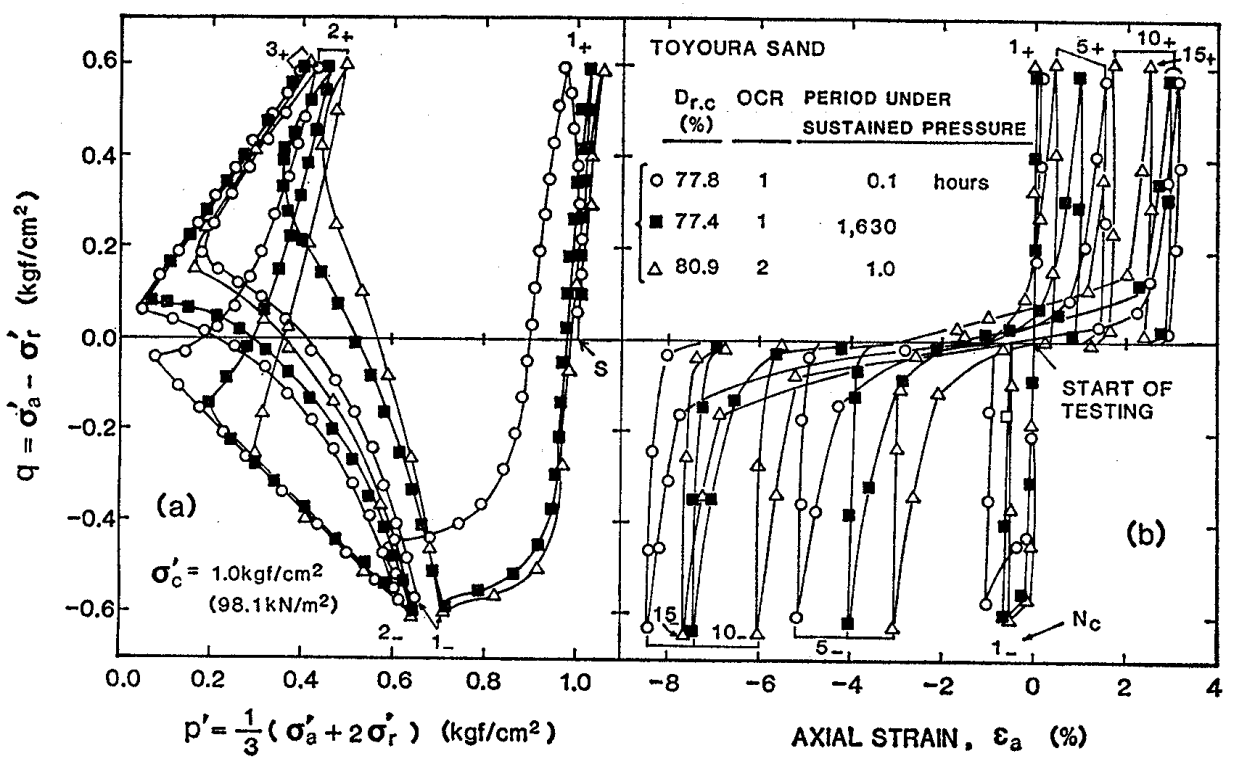

Fig. 6. Effects of sustained compression for 68 days and overconsolidation of $\mathrm{OCR}=2$ on (a) stress path and (b) stressstrain relation for dense Toyoura sand (stresses are not corrected for membrane forces in Figs. 6, 7 and 9)

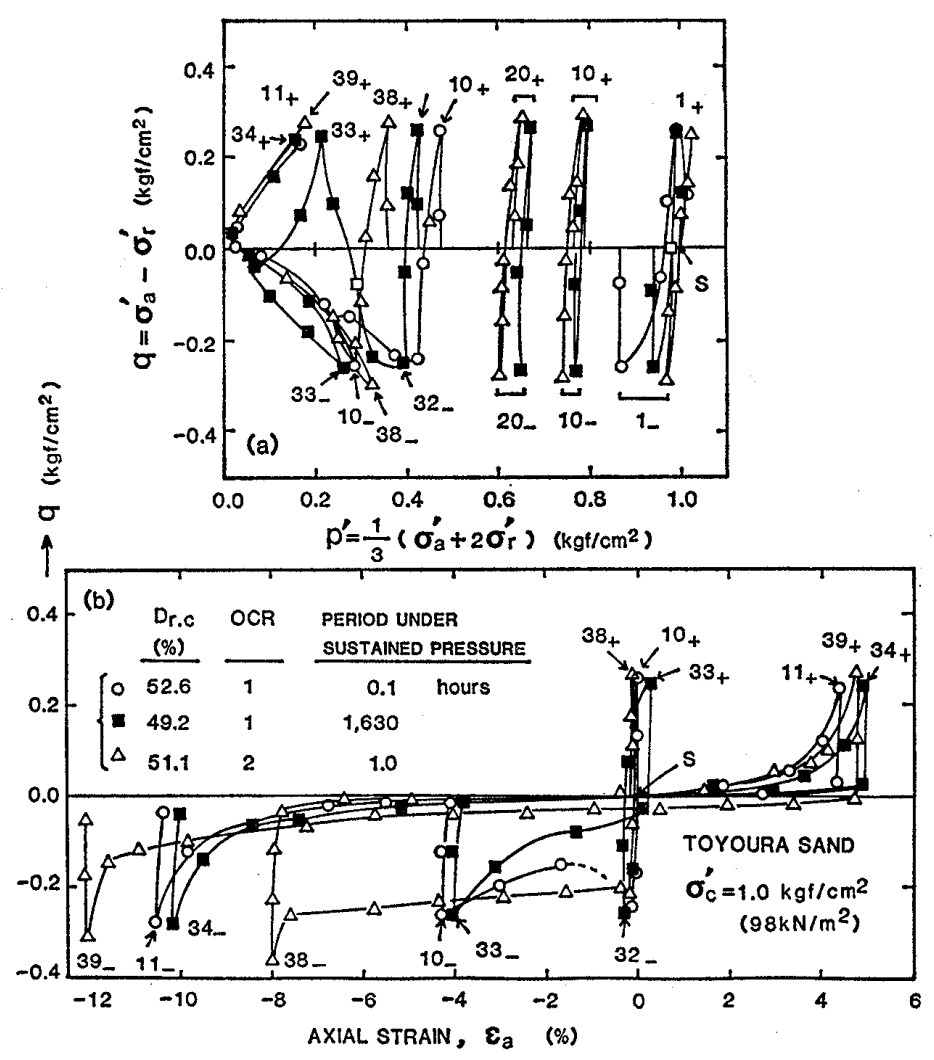

Fig. 7. Effects of long-term consolidation for 68 days and over-consolidation of $O C R=2$ on (a) stress path and (b) stress-strain relation for loose Toyoura sand 
Table 1. List of test results (for Toyoura Sand) $\left(\sigma_{c}{ }^{\prime}=1.0 \mathrm{kgf} / \mathrm{cm}^{2}=98 \mathrm{kN} / \mathrm{m}^{2}\right)$

\begin{tabular}{|c|c|c|c|c|c|c|c|c|}
\hline \multirow{3}{*}{$\begin{array}{l}(1) \\
D_{r . c} \\
(\%)\end{array}$} & \multirow{3}{*}{ 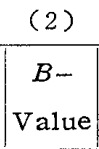 } & \multirow{3}{*}{ OCR } & \multicolumn{2}{|l|}{ (3) } & \multicolumn{4}{|c|}{ (4) } \\
\hline & & & \multirow{2}{*}{$\begin{array}{c}t_{c} \\
(\mathrm{hr})\end{array}$} & \multirow{2}{*}{$\left|\frac{\sigma_{d}}{2 \sigma_{\sigma^{\prime}}}\right|$} & \multicolumn{4}{|c|}{$N_{0}$ to $D A(\%)=$} \\
\hline & & & & & 1 & 2 & 5 & 10 \\
\hline 78.1 & 0.98 & \multirow{6}{*}{1} & \multirow{6}{*}{0.1} & $0.459 \mid$ & 0.25 & 0.60 & 1.9 & 4.8 \\
\hline 77.8 & 0.98 & & & $|0.288|$ & 0.70 & 1.5 & 3.5 & 7.5 \\
\hline 79.7 & 0.93 & & & 0.200 & 6.4 & 7.7 & 10.2 & 15.8 \\
\hline 78.8 & 0.99 & & & $|0.174|$ & 17.6 & 18.7 & 21 & 26 \\
\hline 49.2 & 1.00 & & & $0.145 \mid$ & 3.2 & 3.3 & 3.75 & 3.85 \\
\hline 52.6 & 0.99 & & & 0.131 & 9.2 & 9.3 & 9.8 & 10.0 \\
\hline 81.4 & 0.98 & \multirow{10}{*}{1} & \multirow{10}{*}{1} & 0.198 & & 14.8 & 19.8 & 31 \\
\hline 78.6 & 0.99 & & & 0.174 & & 55 & 58 & 64 \\
\hline 78.9 & 0.97 & & & 0.296 & 0.75 & 1.75 & 4.3 & 9.3 \\
\hline 79.5 & 1.00 & & & 0.491 & 0.28 & 0.73 & 2.45 & 6.2 \\
\hline 48.7 & 0.98 & & & 0.130 & & 9.0 & 9.3 & 9.8 \\
\hline 45.0 & 1.00 & & & 0.148 & 1.0 & 1.15 & 1.3 & 1.65 \\
\hline 52.3 & 0.98 & & & 0.178 & 0.25 & 0.3 & 0.6 & 0.8 \\
\hline 54.1 & 0.99 & & & 0.173 & 1. 3 & 1.45 & 1.7 & 2.0 \\
\hline 48.7 & 1.00 & & & 0.118 & 17.0 & 17.2 & 17.5 & 17.8 \\
\hline 49.0 & 0.98 & & & 0.156 & 1.1 & 1.25 & 1.5 & 1.8 \\
\hline 82.0 & 0.99 & \multirow{8}{*}{1} & \multirow{8}{*}{16} & 0.301 & & 2.8 & 5.7 & 12.6 \\
\hline 77.7 & 0.99 & & & 0.195 & 27 & 29 & 34 & 47 \\
\hline 82.8 & 0.98 & & & 0.297 & 1.0 & 2.0 & 5.3 & 14.5 \\
\hline 77.5 & 0.98 & & & 0.493 & 0.3 & 0.68 & 2. 05 & 5.2 \\
\hline 53.6 & 0.99 & & & 0.170 & & 1.0 & 1.2 & 1.5 \\
\hline 47.4 & 0.99 & & & 0.126 & 2.9 & 3.05 & 3. 25 & 3.6 \\
\hline 49.3 & 0.99 & & & 0.105 & 47 & 49 & 49 & 50 \\
\hline 46.4 & 0.99 & & & 0.148 & 0.9 & 1.05 & 1.25 & 1.65 \\
\hline 81.4 & 0.99 & \multirow{5}{*}{1} & \multirow{5}{*}{64} & 0.197 & 21 & 22 & 26 & 38 \\
\hline 78.4 & 0.99 & & & 0.491 & 0.25 & 0.7 & 2. 23 & 5.7 \\
\hline 80.5 & 0.98 & & & 0.289 & 0.75 & 1.75 & 4.0 & 6.8 \\
\hline 48.3 & 0.98 & & & 0.143 & 6.1 & 6.25 & 6.5 & 6.8 \\
\hline 50.0 & 0.99 & & & $|0.127|$ & 17.9 & 18. 1 & 18.4 & 18.8 \\
\hline 78.2 & 0.98 & \multirow{6}{*}{1} & \multirow{6}{*}{1632} & 0.489 & 0.25 & 0.7 & 2.25 & $5.7 \vdots$ \\
\hline 78.4 & 0.97 & & & 0.266 & 0.85 & 1.7 & 4.1 & 9.8 \\
\hline 75.6 & 0.97 & & & 0.202 & 9.0 & 10.1 & 12.2 & 17.3 \\
\hline 74.6 & 0.98 & & & 0.175 & 92 & 94 & 97 & 106 \\
\hline 77.4 & 0.97 & & & 0.296 & 1.2 & 2.25 & 4.7 & 9.2 \\
\hline 46.8 & 0.98 & & & 0.145 & 12.2 & 12.3 & 12.6 & 12.8 \\
\hline 49.1 & 0.99 & 1 & 1656 & 0.133 & 31 & 31 & 32 & 32 \\
\hline 51.1 & 0.97 & 1 & 1696 & 0.177 & 2.3 & 2.4 & 2.7 & 2.95 \\
\hline 80.9 & 0.98 & & & 0.298 & 1.8 & 3.0 & 6.0 & 14 \\
\hline 74.8 & 0.96 & & & 0.200 & $85^{\circ}$ & 87 & 90 & 97 \\
\hline 80.7 & 0.98 & & & 0.246 & 1.5 & 3.5 & 8.0 & 18 \\
\hline 83.2 & 0.99 & 2 & 1 & 0.498 & 0.75 & 1.5 & 4.8 & 14 \\
\hline 60.7 & 0.98 & 2 & 1 & 0.128 & & & & 349 \\
\hline 50.8 & 0.98 & & & $0.155 \mid$ & & & & 9.0 \\
\hline 40.2 & 0.98 & & & 0.181 & & & & 1.7. \\
\hline 51.1 & 0.99 & & & $|0.138|$ & & $\cdots$ & & 38 \\
\hline 80.0 & 0.96 & & & 0.309 & 5.0 & 6.5 & 9.8 & 17 \\
\hline 81.5 & 0.99 & & & 0.260 & 537 & 540 & 543 & 553 \\
\hline 82.1 & 0.99 & 4 & 1 & 0.498 & 0.7 & 1.65 & 4.3 & 10.2 \\
\hline 46.5 & 0.98 & 4 & 1 & 0.182 & & & & 90 \\
\hline 50.2 & 0.98 & & & 0.155 & & & & 69 \\
\hline 46.2 & 0.98 & & & 0.204 & & & & 6.3 \\
\hline
\end{tabular}

(1) the value during cyclic undrained loading,

(2) as measured just prior to cyclic undrained loading by decreasing the cell pressure,

(3) period under sustained presșure, for overconsolidated specimens, period under pre-loading,

(4) as measured; prior to correction. (for Sengenyama Sand)

$\left(\sigma_{c}{ }^{\prime}=1.333 \mathrm{kgf} / \mathrm{cm}^{2}=131 \mathrm{kN} / \mathrm{m}^{2}\right)$

\begin{tabular}{|c|c|c|c|c|c|c|c|c|}
\hline \multirow{2}{*}{$\begin{array}{l}D_{r .0} \\
(\%)\end{array}$} & \multirow{2}{*}{$\begin{array}{c}B- \\
\text { Value }\end{array}$} & \multirow{2}{*}{ OCR } & \multirow{2}{*}{$\begin{array}{c}t_{c} \\
(\mathrm{hr})\end{array}$} & \multirow{2}{*}{$\frac{\sigma_{d}}{2 \sigma_{\sigma^{\prime}}^{\prime}}$} & \multicolumn{4}{|c|}{$N_{c}$ to $D A(\%)=$} \\
\hline & & & & & 1 & 2 & 5 & 10 \\
\hline $\begin{array}{l}79.7 \\
80.8 \\
79.7\end{array}$ & $\begin{array}{l}1.00 \\
0.99 \\
1.00\end{array}$ & 1 & 0.1 & $\begin{array}{l}0.298 \\
0.254 \\
0.498\end{array}$ & $\begin{array}{l}5.7 \\
21\end{array}$ & $\begin{array}{c}8.2 \\
24\end{array}$ & $\begin{array}{l}12.2 \\
28 \\
3.45\end{array}$ & $\begin{array}{l}15.9 \\
32 \\
5.8\end{array}$ \\
\hline 78.2 & 0.98 & & & 0.198 & 36 & 38 & 40 & 40 \\
\hline 75.4 & 0.99 & & & 0.200 & 11.2 & 12.6 & 3.2 & 15.6 \\
\hline 78.5 & 0.96 & & & 0.201 & 41 & 44 & 47 & 49 \\
\hline 86.2 & 0.99 & & & 0.203 & 84 & 87 & 92 & 97 \\
\hline 78.5 & 0.98 & & & 0.247 & 3.9 & 5.3 & 7.3 & 10.1 \\
\hline 81.1 & 0.97 & & & 0.250 & 10.7 & 13.2 & 16.7 & 21 \\
\hline 31.6 & 0.97 & & & 0.251 & 5.6 & 7.6 & 10.6 & 13.3 \\
\hline 85.3 & 1.00 & & & 0.252 & 17 & 20 & 25 & 29 \\
\hline 75.1 & 1.00 & & & 0.296 & 1.76 & 3.0 & 5.2 & 6.0 \\
\hline 75.4 & 0.96 & 1 & 1 & 0.299 & 0.8 & 2.2 & 4.1 & 6.1 \\
\hline 79.4 & 1.00 & & & 0.300 & 6.1 & 9.8 & 13.7 & 16.7 \\
\hline 79.9 & 0.99 & & & 0.301 & 3.3 & 5.6 & 2 & 13 \\
\hline 80.2 & 1.00 & & & .0 .401 & & 3.2 & 0 & 10.2 \\
\hline 76.8 & 0.96 & & & 0.401 & & & 2.21 & 3.96 \\
\hline 84.5 & 0.96 & & & 0.403 & & 1.82 & 4.6 & 7.2 \\
\hline 31.1 & 0.96 & & & 0.497 & & & 2.1 & 3.82 \\
\hline 31.6 & 0.99 & & & 0.500 & & 1.7 & 4.2 & 8.6 \\
\hline 4.9 & 0.99 & & & 0.507 & & & 1.8 & 3. 38 \\
\hline 87.6 & 0.99 & & & 0.508 & & 1.14 & 3.94 & 7.1 \\
\hline .5 & & & & 298 & 4.2 & 6. & 10. & 14.7 \\
\hline 8 & & 1 & 16 & 0.508 & & & 4. & 7.8 \\
\hline 4 & 1.00 & 1 & 10 & 0.201 & 180 & 184 & 188 & 192 \\
\hline 0.5 & 0.98 & & & $0.250_{i}^{1}$ & 19.9 & 23 & 27 & 31 \\
\hline 2.8 & 0. & & & 0.209 & 227 & 232 & 238 & 245 \\
\hline .9 & & 1 & 64 & 0.296 & 7.8 & 11. & 16 & 21 \\
\hline .9 & 0. & . & 04 & 0.252 & 21 & 24 & 29 & 33 \\
\hline 9,9 & 1.00 & & & 0.496 & & & 4.1 & 7.5 \\
\hline 4 & 0.99 & & & 0.397 & 2.4 & 4. & 8. & 13.6 \\
\hline 4 & & & & 0.295 & 7 & 10. & 13. & 17.2 \\
\hline 2.2 & 1. & 1 & 1630 & 0.252 & 92 & 99 & 107 & 114 \\
\hline 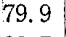 & 1. & & & 0.200 & & & & 279 \\
\hline 82.7 & 1.00 & & & 0.279 & 26 & 30 & 36 & 42 \\
\hline 1.4 & 0.98 & & & 0.300 & 38 & 43 & 50 & 55 \\
\hline 5 & & & & 0.396 & 3. & 6. & 11.4 & 16.3 \\
\hline 5 & 1: & & & 0.249 & 266 & 270 & 275 & 279 \\
\hline 1.1 & & 2 & 1 & 0.282 & 24 & 27 & 31. & 34 \\
\hline 30.2 & & & & 0.504 & & 1. & 4.9 & 7.7 \\
\hline 83. & & & & 297 & 23 & 26 & 32 & 37 \\
\hline 81.6 & 0.9 & & & 0.305 & 19. 2 & 22 & 26 & 30 \\
\hline 32.5 & & & & 0.344 & 55 & 60 & 65 & 70 \\
\hline 1 & & & & 549 & & 3. & 6. & 9.2 \\
\hline 79. & & 4 & 1 & 0.356 & 22 & 26 & 31 & 35 \\
\hline 81.9 & & 4 & 1 & 0.301 & 239 & 243 & 249 & 254 \\
\hline 31.4 & & & & 0.454 & 3.2 & 5. & 9.5 & 12.8 \\
\hline 82.8 & 0.98 & & & 0.501 & & 2.2 & 4.8 & 7.3 \\
\hline 80.5 & 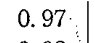 & & & 304 & 33 & 37 & 41 & 45 \\
\hline 79.4 & & & & 495 & & 2.3 & 5.2 & 7.9 \\
\hline 88. & & & 16 & 0.255 & 107 & 110 & 114 & 117 \\
\hline 81.6 & & 2 & 10 & 0.404 & 1.95 & 4. & 7.0 & 10.0 \\
\hline 79.1 & & 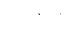 & & 0.237 & 246 & 249 & 254 & 257 \\
\hline 78.0 & 0.98 & & & 0.358 & 5. & 7.1 & 11.4 & 14.7 \\
\hline 79.1 & 0. & & & 300 & 19 & 22 & 26 & 30 \\
\hline 81. & & & & 0.265 & 85 & 89 & 93 & 98 \\
\hline 80. & & 2 & 64 & 0.249 & 97 & 100 & 104 & 108 \\
\hline 70 & & 2 & 04 & 0.500 & & 1 & 3. & 6.4 \\
\hline 80.5 & 0. & & & 0.458 & 1.38 & 3.24 & 6.4 & 9.1 \\
\hline 82.2 & 0.97 & & $\therefore 1$ & 0.393 & 4.5 & 7.8 & 12.5 & 17.4 \\
\hline
\end{tabular}



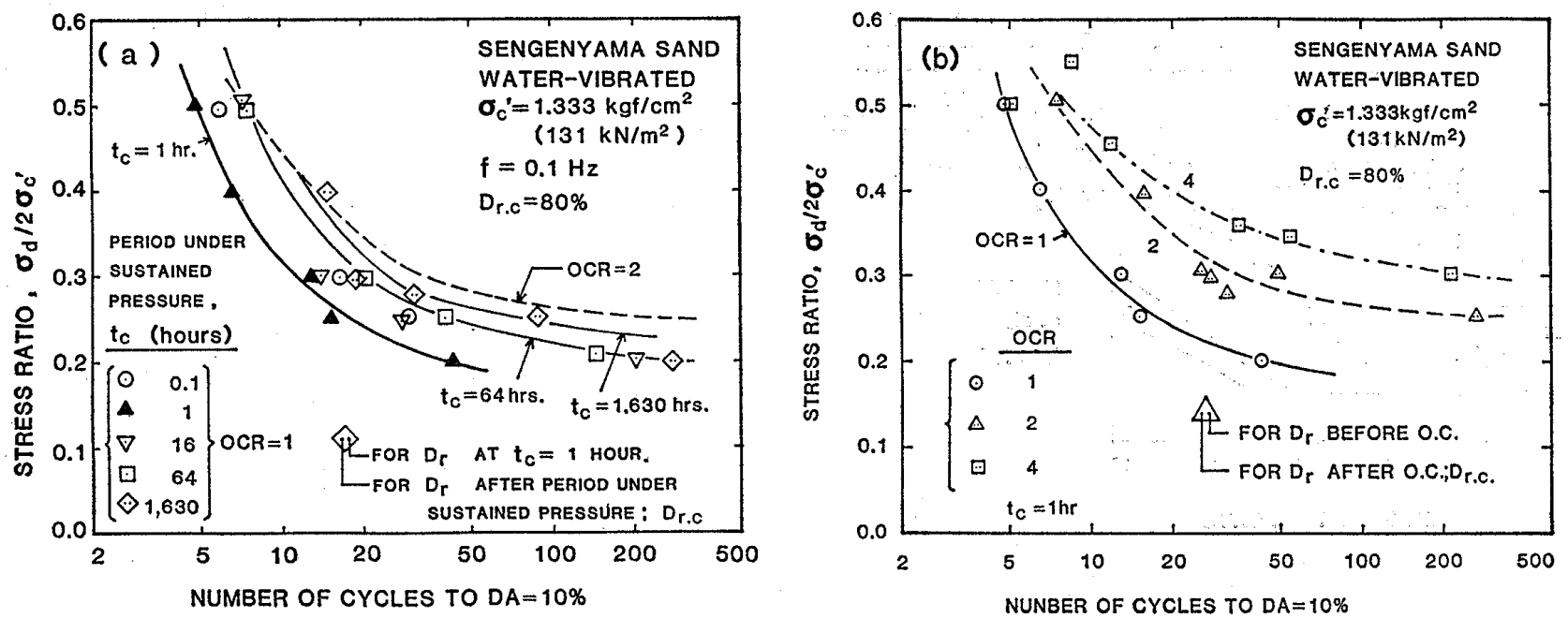

Fig. 8. Effects of (a) sustained compression and (b) over-consolidation on liquefaction strength of dense Sengenyama sand
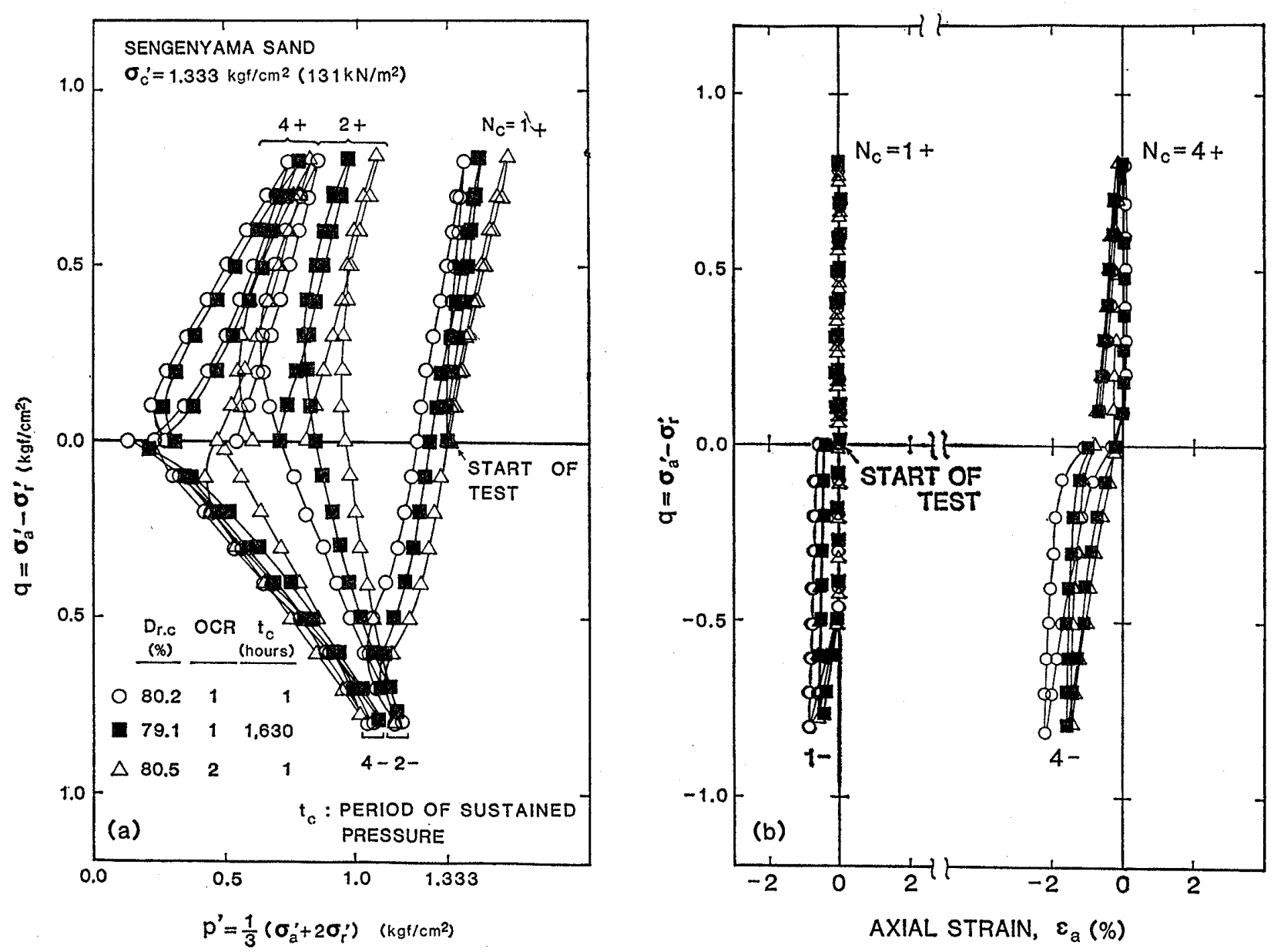

Fig. 9. Effects of long-term consolidation for 68 days and over-consolidation of $\mathrm{OCR}=2$ on (a) stress path and (b) stress-strain relation for dense Sengenyama sand 


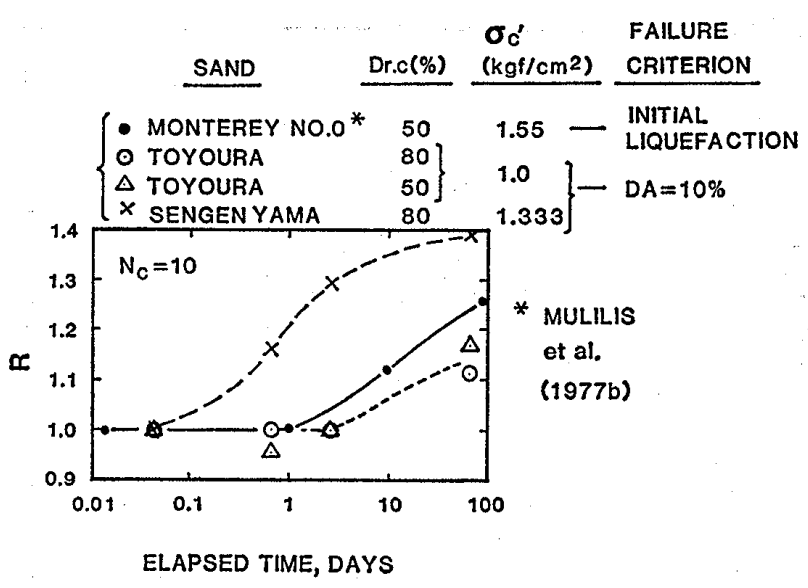

Fig. 10. Increase in strength of three sands due to long-term consolidation

$10 \%$ can be used for defining the failure of sand subjected to cyclic undrained loading.

In this paper, a value of $D A=10 \%$ was selected since too small values of $D A$ such as $2 \%$ seemed inappropriate to use for defining the resistance of dense sands against cyclic undrained loading; for a $D A=2 \%$ or a similar small $D A$, the effects of density on the strength becomes too small. This point has been discussed in detail by Tatsuoka et al. (1982). However, it was confirmed that the conclusions as to the effects of long-term consolidation and over-consolidation on cyclic undrained strength do not change even when a $D A$ smaller than $10 \%$ is used for defining the failure. The values of $N_{c}$ to $D A=2 \%$ or $5 \%$ as well as those to $D A=10 \%$ are listed in Table 1.

Similar results as for Toyoura sand were obtained also for dense $\left(D_{r . c}=80 \%\right)$ Sengenyama sand (Figs. 8 and 9). For Sengenyama sand specimens normally consolidated for one hour, the average relationship between $D_{r . c}$ and $N_{c}$ to $D A=10 \%$ for each cyclic stress ratio was newly defined for the range of $D_{r . c}=75 \sim 85 \%$. The values of $N_{c}$ for $D_{r . c}=80 \%$ were obtained from these relationships. On the other hand, for longterm consolidated or over-consolidated specimens, the value of $N_{c}$ for each test data was corrected to the value for $D_{r . c}=80 \%$ using the relationships as described above as performed for Toyoura sand. In Figs. 8 and 9, two kinds of the number of loading cycles
$N_{c}$ corrected to a relative density of $80 \%$ are shown for each specimen either consolidated for 1,630 hours (68 days) or over-consolidated; these are the values determined (1) for the relative density $D_{r}$ prior to either long-term consolidation or over-consolidation (i. e., $D_{r}$ at the point $\mathrm{A}$ in Fig. 1), and (2) for the relative density $D_{r . c}$ during cyclic loading. It may be seen that the differences between two kinds of $N_{c}$ are very small. This point was confirmed for Toyoura sand too. Therefore, only the strength values defined for $D_{r . c}$ will be used hereafter.

It may be seen from these figures that the liquefaction strength increased due to both long-term consolidation and over-consolidation. The effects of either long-term consolidation or over-consolidation can be clearly seen also in Figs. 6,7 and 9. It may be seen that the tendency of negative dilatancy in the first cycle has decreased considerably for specimens subjected to long-term consolidation for 68 days or over-consolidation of $\mathrm{OCR}=2$. It may be seen further from Figs. 4 through 9 that in each case the increase in liquefaction strength due to long-term consolidation for 68 days is approximately equivalent to that due to over-consolidation of $\mathrm{OCR}=2$.

Fig. 10 compares the results obtained by the present study with that for Monterey No. 0 sand. The ratio $R$ is defined as the ratio of cyclic stress ratio $\sigma_{d} / 2 \sigma_{c}{ }^{\prime}$ required to cause failure in ten cycles between specimens after periods under sustained pressure and freshly deposited specimens; $\sigma_{d}$ is the single amplitude of cyclic deviator stress and $\sigma_{c}{ }^{\prime}$ is the initial effective confining pressure (i. e., $\left(\sigma_{c}{ }^{\prime}\right)_{\text {test }}$ in Fig. 1). A cycle of ten was selected since only $R$ for this cycle has been presented by Mulilis et al. (1977 b). For the data obtained by the present study, $R$ at an elaspsed time of 1 hour was defined as 1.0. It may be seen that the increase in $R$ after periods under sustained pressure for Toyoura sand is lower than that for Monterey No. 0 sand, whereas that for Sengenyama sand is larger than that for Monterey No. 0 sand.

It may be noticed by carefully observing the data shown in Figs. 4(a), 4(b) and Fig. 


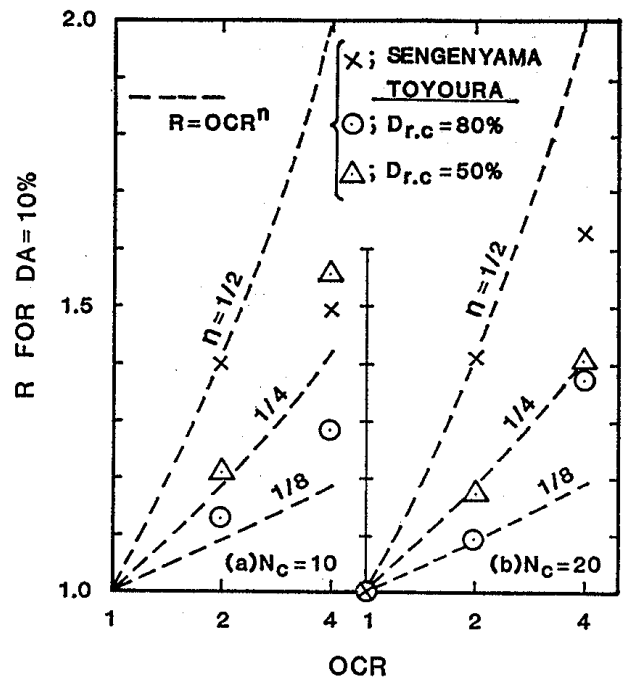

Fig. 11. Increase in strength due to over-consolidation

8 that the strength decreases slightly with time in some cases where the period under sustained pressure is less than 16 hours, although this strength decrease is masked to a large extent by the scattering of data. At present, it is conceivable that this strength decrease is due partly to the increase in plastic deformation of membrane with time; the recovery of membrane penetration which takes place by the increase in pore water pressure during cyclic loading may be reduced by this increased plastic deformation of membrane and thereby the liquefaction strength is reduced.

Fig. 11 shows the increase in strength due to over-consolidation, where the strength is expressed in terms of the ratio $R$ of strength between over-consolidated and normally consolidated specimens for the failure defined for $D A=10 \%$ in either ten or twenty cycles. It may be seen that the increase in strength due to over-consolidation is generally larger for Sengenyama sand than for Toyoura sand. The data points scatter between two lines representing the relationships $R=\mathrm{OCR}^{n}$ with $n=1 / 2$ and $1 / 8$. Ishihara and Takatsu (1977) showed that the power $n$ is $1 / 2$ for Fuji river sand for the failure defined for initial liquefaction in twenty cycles. The results shown in Fig. 11 together with those by Ishihara and Takatsu (1977) suggest that the power $n$ can be very different for different sands. On the other hand, the results shown in Figs. 10 and 11 should be treated with caution since in some cases the cyclic stress ratio required for failure in a certain cycles of loading may not appropriately represent the entire feature of such strength curves as shown in Figs. 4,5 and 8. It shoudl be noted, further, that the simple shear liquefaction strength of a specimen consolidated one-dimensionally may be larger than that predicted from $R=\mathrm{OCR}^{n}$ by using the values of $n$ presented in Fig. 11 and also OCR defined as the ratio of the maximum past vertical stress to the present vertical stress. This is due to the fact that the ratio $K=\sigma_{h}{ }^{\prime} / \sigma_{v}{ }^{\prime}$ (effective horizontal stress to effective vertical stress) increases during unloading as OCR increases.

Strength Curves; It may be seen in Figs. 4 (a), 5(a) and 8 that for dense sands the cyclic stress ratio required to cause a certain value of axial strain amplitude in a certain cycles of loading $N_{c}$ is very sensitive to the change in $N_{c}$ for $N_{c}$ less than a certain value. For example, in Figs. 4(a) and 5(a), the cyclic stress ratio required to cause $10 \%$ $D A$ in 5 cycles is much larger than that in 10 cycles. Consequently, as discussed in Tatsuoka et al. (1986 b), it can be very misleading in some cases to represent the liquefaction strength of dense sand solely in terms of such cyclic stress ratios as described above.

Fig. 12 shows strength curves of air-pluviated Toyoura sand of various densities which had been normally consolidated for 1 hour. It may be seen by comparing Fig. 12 with Figs. 4(a) and 5(a) that especially for dense specimens the change in the shape of strength curve by the change in density as seen in Fig. 12 is different from either that by the change in long-term consolidation period as seen in Fig. 4(a) or that by the change in OCR as seen in Fig. 5(a). Namely, for the data obtained by the present study, the rate of the increase in cyclic stress ratio required to cause $10 \% D A$ in a certain small value of $N_{c}$, say less than 10, either by longterm consolidation or by over-consolidation 


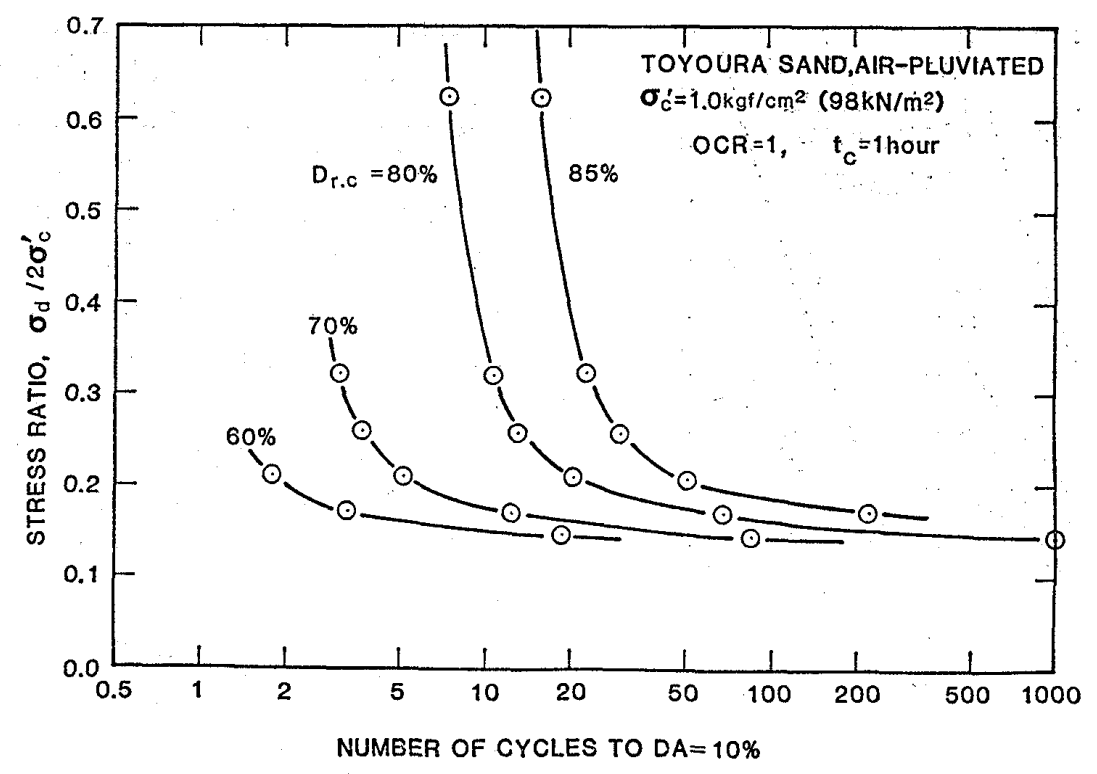

Fig. 12. Liquefaction strength curves for air-pluviated Toyoura sand, normally consolidated for one hour (reproduced from Fig.8 of Tatsuoka et al., 1986b)

is considerably smaller than that by the increase in density. However, at larger values of $N_{\mathrm{c}}$, the opposite is true.

Unfortunately, it has not been shown for Monterey No. 0 sand how the strength curves such as shown in Figs. 4, 5 and 8 change after periods under sustained pressure, but only the data presented in Fig. 10 have been published. Therefore, such a kind of discussion as above cannot be made for Monterey No. 0 sand.

On the other hand, Yoshimi et al. (1984) have shown that for the same density the cyclic undrained triaxial strength curves for high-quality undisturbed dense Niigata sand specimens and those for its reconstituted specimens are considerably different; i. e., the stress ratio required to cause $5 \% D A$ in the number of cycles $N_{c} \fallingdotseq 4 \sim 100$ is much larger for the undisturbed specimens than for the reconstituted specimens. Although it is to a much lesser extent, this tendency can be seen also in the data obtained by the present study between dense specimens normally consolidated for a short duration and either those normally consolidated for a long duration or those over-consolidated (Figs. 4(a), 5(a) and 8). Therefore, it is probable that a part of the increased strength of the in situ dense Niigata sand has been gained by either long-term consolidation or over-consolidation or both.

It has been shown that for the same density such strength curves of sands as shown in Figs. 4, 5, 8 and 12 are considerably different for different sample preparation methods (Mulilis et al., $1977 \mathrm{a}$; Tatsuoka et al., $1986 \mathrm{~b}$ among others). Now, it is apparent that the location and shape of the strength curve in such a plot as shown in Figs. 4, 5, 8 and 12 may change considerably by many variables such as described above. On the other hand, it has been shown that the resistance against a given irregular loading for a certain sand specimen is closely related to the whole of such a strength curve as described above (Tatsuoka et al., 1986a). In view of the above, it is appropriate to report the whole of such a strength curve as above obtained by performing a series of cyclic undrained testing. It is not sufficient to define a single strength value in terms of such a single stress ratio as defined for failure in a certain cycle of loading.

Some Insight into the Mechanism; Fig. 13 shows the relationships between the ratio $R$ and plastic (irrecoverable) axial strains for both specimens normally consolidated for var- 


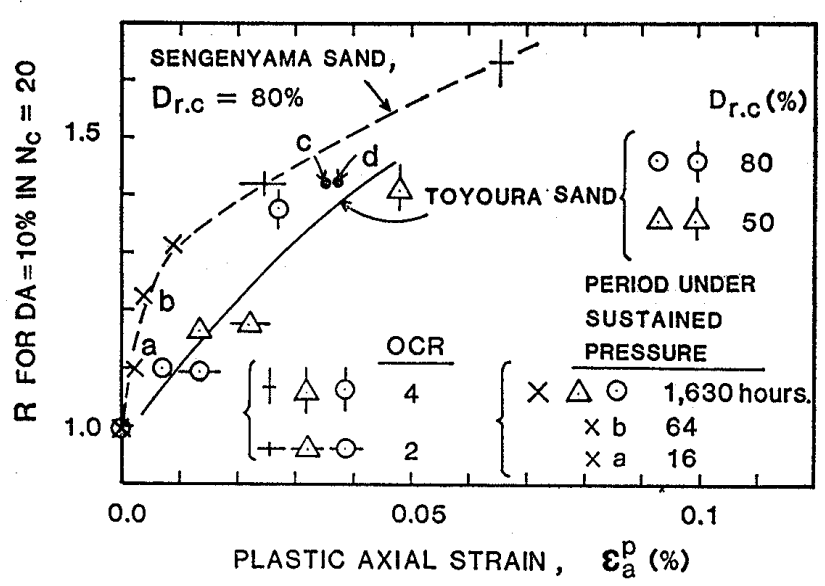

Fig. 13. Relationship between strength increase due to long-term consolidation or over-consolidation and plastic axial strain (the data points $c$ and $d$ are for Sengenyama sand of $D_{r . c}=80 \%$, overconsolidated at $O C R=2$ for 16 hours (c) or 64 hours (d))

ious periods and those over-consolidated. In this figure, the ratio $R$ is defined for $N_{c}=$ 20 since $R$ can be defined with larger confidence for $N_{c}=20$ than for $N_{c}=10$. The plastic axial strain $\varepsilon_{a}^{p}$ is defined as the one caused either by over-consolidation stress history or by long-term consolidation after normal consolidation of an elapsed time of 1 hour. The value of $\varepsilon_{a}^{p}$ for each data point in Fig. 13 has been averaged for several similar test data.

It may be seen in Fig. 13 that for each sand, the relationship is similar between specimens normally consolidated for various periods and those over-consolidated. This result may suggest that the increase in strength due to long-term consolidation and over-consolidation observed in the present study is due largely to a slight movement of the sand grains into a more stable position associating plastic strain, but not due to some form of cementation occurring at the contact points of the sand grains. This is because this second mechanism is not likely to occur during an over-consolidation stress history of only 1 hour.

The strength increase either for the same period under sustained pressure or for the same OCR is larger for Sengenyama sand

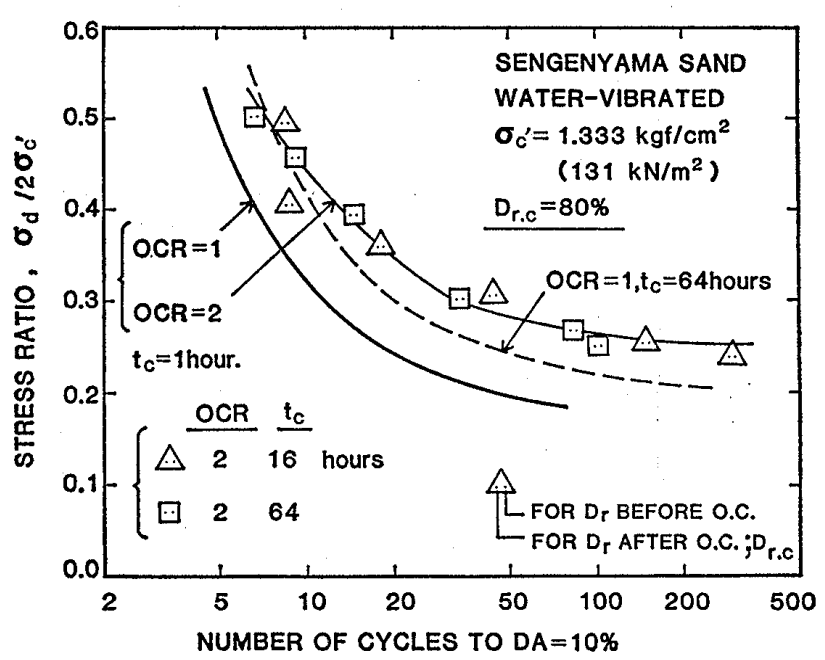

Fig. 14. Effects of over-consolidation for periods on liquefaction strength of Sengenyama sand

than Toyoura sand. This may be due partly to different amount of fines.

One may consider that if a long-term consolidation at a stress level larger than that at which a cyclic loading test is performed is applied to a specimen, the strength increases due to the doubled effects of long-term consolidation and over-consolidation. However, it was found, as shown in Fig. 14, that for $\mathrm{OCR}=2$ the strength of specimens over-consolidated for 16 or 64 hours is essentially similar to that of specimens over-consolidated for 1 hour. This point is clearly seen also in Fig. 15. This result suggests that for over-consolidated sands the effect of longterm consolidation may not be expected. The data points denoted by the letters $\mathrm{c}$ and d in Fig. 13 represent those over-consolidated for 16 hours and 64 hours. It may be seen that for these specimens $\varepsilon_{a}^{p}$ increased to some extent during long-term over-consolidation although $R$ did not increase. It is to be noted that the range of tests performed in the present study is too limited. In order to reach any conclusion in this respect, more research works are required.

The results obtained by the present study suggest that an application of preloading for providing an OCR of the order of two is not an effective measures to decrease the susceptibility to liquefaction of a sand stratum since 

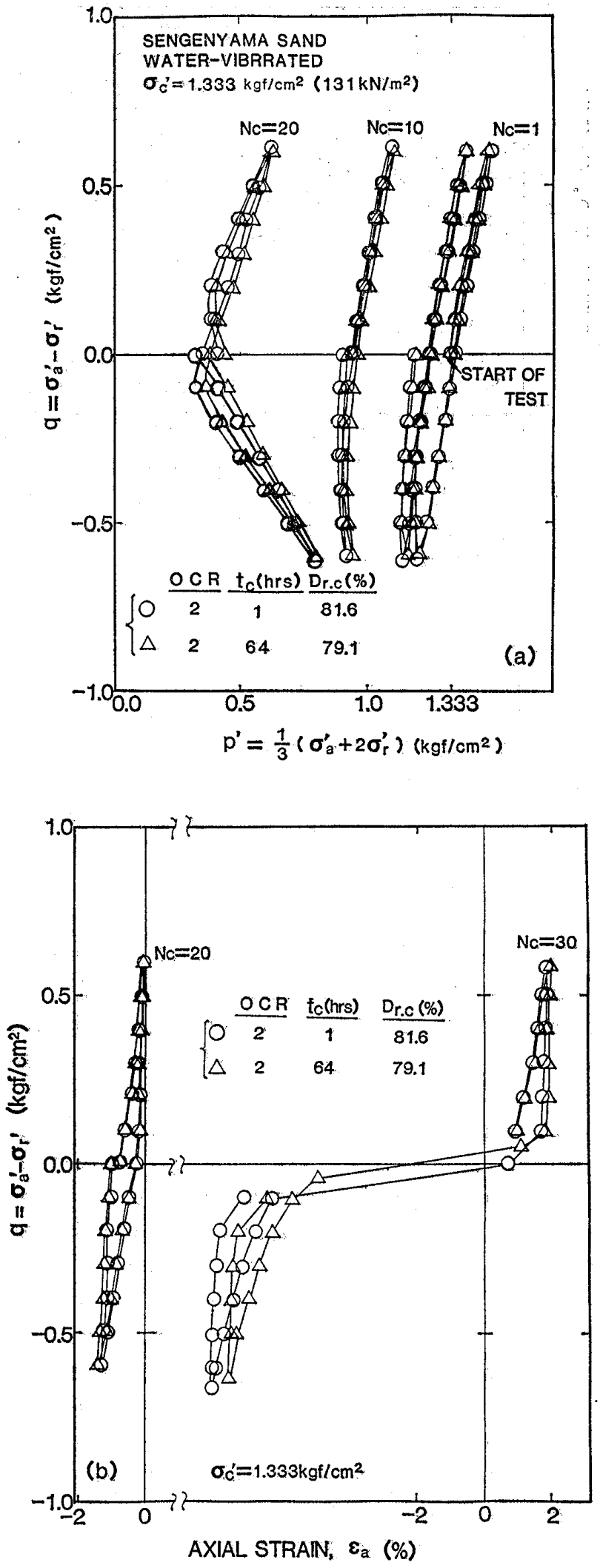

Fig. 15. Comparison of (a) stress path and (b) stress-strain relation between two specimens of Sengenyama sand overconsolidated for one hour and 64 hours a comparable strength increase can be gained only after several months without the application of preloading. It is to be noted that it is not a simple task to apply an OCR of two to a sand stratum, for example, at a depth of five meters. The compaction of sand is much more effective.

Despite some data showing the strength increase after periods under sustained pressures have been obtained, it still remains necessary to study how this aging effect for a duration longer than 68 days can be reasonably estimated from such data and how this aging effect is to be taken into account in the actual design procedure.

\section{CONCLUSIONS}

The following conclusions can be derived on the basis of the limited number of the test results :

(1) For two kinds of saturated sands, the resistance against undrained cyclic loading increased to some extent after 68 days under sustained pressure.

(2) This strength increase due to longterm consolidation was equivalent to that obtained by over-consolidation with an OCR of about two.

(3) For dense specimens, the rate of strength increase due to both long-term consolidation and over-consolidation was larger for strength values defined for failure in larger cycles of loading.

(4) The strength increase due to longterm consolidation and over-consolidation and associated plastic axial strains were larger for Sengenyama sand including some fines than a clean sand called Toyoura sand.

(5) For Sengenyama sand, the strengths of specimens over-consolidated for different periods were similar. This means that the effects of long-term consolidation and overconsolidation are coupled in a specific way. 


\section{ACKNOWLEDGEMENTS}

The authors would like to express their appreciation to Messrs. T. Sato and S. Yamada and Miss M. Torimitsu who cooperated with the authors in this research project. This study was supported by a grant-in-aid of the Ministry of Education, Science and Culture of the Japanese Government. Many thanks go also to the Japan Highway Public Corporation for its financial support.

\section{REFERENCES}

1) Banerjee, N.G., Seed, H. B. and Chan, C.K. (1979): "Cyclic behavior of dense coarse-grained materials in relation to the seismic stability of dams," Report to Calif. Dept. of Water Resources, No. UCB/EERC-79/113, EERC, Univ. California, Berkeley, Calif.

2) Ishihara, K. and Takatsu, H. (1979): "Effects of over-consolidation and $K_{0}$ condition on the liquefaction characteristics of sands," Soils and Foundations, Vol.19, No.4, pp. 59-68.

3) Mulilis, J. P., Seed, H. B., Chan, C. K., Mitchell, J. K. and Arulanandan, K. (1977 a): "Effects of sample preparation on sand liquefaction," Jour. of the GT Div., Proc., ASCE, Vol.103, No. GT 2, pp. 91-108.

4) Mulilis, P., Mori, K., Seed, H. B. and Chan, C. K. (1977 b): "Resistance to liquefaction due to sustained pressure," Jour. GE Div., Proc., ASCE, Vol.103, No. GT 7, July, pp. 793-797.

5) Tatsuoka, F., Muramatsu, M. and Sasaki, T. (1982): "Cyclic undrained stress-strain behavior of dense sands by torsional simple shear," Soils and Foundations, Vol.22, No.2, pp. 5570.

6) Tatsuoka, F., Maeda, S., Ochi, K. and Fujii, S. (1986 a) : "Prediction of cyclic undrained strength of sand subjected to irregular loadings," Soils and Foundations, Vol. 26, No.2, pp. 73-90.

7) Tatsuoka, F., Ochi, K., Fujii, S. and Okamoto, M. (1986 b) : "Cyclic undrained triaxial and torsional shear strength of sands for different sample preparation methods," Soils and Foundations, Vol.26, No.3, pp. 23-41.

8) Tatsuoka, F., Toki, S., Miura, S., Kato, H., Okamoto, M., Yamada, S., Yasuda, S. and Tanizawa, F. (1986 c): "Some factors affecting cyclic undrained triaxial strength of sand," Soils and Foundations, Vol.26, No.3, pp. 99-116.

9) Toki, S., Tatsuoka, F., Miura, S., Yoshimi, Y., Yasuda, S. and Makihara, Y. (1986): "Cyclic undrained triaxial strength of sand by a cooperative test program," Soils and Foundations, Vol. 26, No. 3, pp. 117-128.

10) Yoshimi, Y., Tokimatsu, K., Kaneko, O. and Makihara, Y. (1984): "Undrained cyclic shear strength of a dense Niigata sand," Soils and Foundations, Vol.24, No.4, pp.131-145. 